\title{
Complex Seismic Discontinuities in the Mantle Transition Zone beneath NW Himalaya and Ladakh- Karakoram
}

\section{KS Prakasam ${ }^{1}$, SS Rai ${ }^{*}$, Keith Priestley ${ }^{2}$ and VK Gaur ${ }^{3}$}

1 National Geophysical Research Institute, Hyderabad-500007, INDIA

2 Bullard Lab., Cambridge University, Cambridge, UK

3 Indian Institute of Astrophysics, Bangalore, INDIA

* For correspondence, email: shyamsrai@gmail.com

Analyses of mantle converted Ps phase in 957 teleseismic receiver functions calculated from broadband seismograms deployed at 19 sites along a $700 \mathrm{~km}$ long N-S profile from the exposed northern edge of the Indian shield near Delhi to the Ladakh-Karakoram reveal complex features in the underlying Mantle Transition Zone (MTZ). Beneath the Gangetic plain and the Himalaya south of the Indus Zangbo Suture (IZS), the $410-\mathrm{km}$ discontinuity is shallow $(\sim 392 \mathrm{~km})$ and the mantle transition zone is relatively thicker $(\sim 260 \mathrm{~km})$. To the north of the IZS beneath the Ladakh the 410-km discontinuity lies near its normal depth but the transition zone is thinner $(\sim 242 \mathrm{~km})$ and includes an interface at $\sim 475 \mathrm{~km}$ depth. The base of the transition zone is complex as revealed in dominant converted phase from 660 depth and a weaker one at $\sim 715 \mathrm{~km}$. These observations suggest the presence of a high velocity slab within the MTZ beneath the Ladakh region, most likely a broken off segment of the subducted Indian Lithosphere, and the other deeper one beneath Himalaya and Ladakh which is likely the sunken delaminated oceanic lithosphere that was rolled back across the mantle transition zone. 